\title{
Agricultura urbana na cidade de Montes Claros-MG: um breve referencial teórico
}

\section{Urban agriculture in the city of Montes Claros-MG: a brief theoretical reference}

\section{La agricultura urbana en la ciudad de Montes Claros-MG: una breve referência teórica}

Deyvison Lopes de Siqueira - deyvisonsiqueira@yahoo.com.br Mestre em Geografia da Universidade Estadual de Montes Claros -Unimontes Orcid: http://orcid.org/0000-0003-0393-1292

Gustavo Henrique Cepolini Ferreira - gustavo.cepolini@unimontes.br Doutor em Geografia Humana e Professor do Departamento de Geociências e PPGEO Universidade Estadual de Montes Claros - UNIMONTES-Brasil Orcid: http://orcid.org/0000-0003-1010-501X

\begin{abstract}
Resumo
O presente ensaio apresenta parte do referencial teórico sobre o desenvolvimento da agricultura urbana na cidade de Montes Claros-MG. Esse referencial é fruto da pesquisa de dissertação de mestrado, que se adotou como metodologia o estudo de caso em consonância com os elementos da pesquisa participante. Nota-se que as práticas inerentes à Agricultura Urbana (AU) vêm se tornando uma realidade nos grandes centros urbanos, através da produção de diversos alimentos, sendo praticada em quintais, áreas públicas e privadas. Nesse sentido, tais análises permitem concluir que a prática de $\mathrm{AU}$ é desenvolvida no espaço urbano há muito tempo por agricultores(as) de origem rural e urbana, visto que o cultivo de alimentos é praticado por eles(as) em áreas próprias, públicas e cedidas; espaços pequenos em que são cultivados uma diversidade significativa de alimentos a partir de uma transição agroecológica, marcada por uma campesinidade plural, seja na comercialização por meio das alternativas nos mercados locais, bem como no autoconsumo.
\end{abstract}

Palavras-chave: Transição Agroecológica. Espaços Urbanos. Agricultura Urbana. Montes Claros.

\begin{abstract}
This essay presents part of the theoretical framework on the development of urban agriculture in the city of Montes Claros-Minas Gerais. It is the result of the research of the master's thesis, which adopted as methodology the case study in consonance with the elements of the participant research. It is observed that the practices inherent to Urban Agriculture (UA) have become a reality in large urban centers, through the production of various foods, being practiced in backyards, public and private areas. In this sense, such analyzes allow to conclude that the UA practice has been developed in urban space for a long time by farmers of rural and urban origin, since the cultivation of food is practiced by them in their own, public and assigned areas; small spaces in which a significant diversity of food is cultivated from an agroecological transition, marked by a plural peasantry, either in commercialization through alternatives in local markets, as well as in self-consumption.
\end{abstract}

Key words: Agroecological Transition. Urban spaces. Urban agriculture. Montes Claros. 


\section{Resumen}

Este ensayo presenta parte del referencial teórico sobre el desarrollo de la agricultura urbana en la ciudad de Montes Claros-Minas Gerais. El mismo es el resultado de la investigación de la tesis de maestría, que adoptó como metodología el estudio de caso en consonancia con los elementos de la investigación participante. Se observa que las prácticas inherentes a la Agricultura Urbana (AU) se han hecho realidad en los grandes centros urbanos, a través de la producción de diversos alimentos, siendo practicada en patios traseros, áreas públicas y privadas. En este sentido, tales análisis permiten concluir que la práctica de la $\mathrm{AU}$ ha sido desarrollada en el espacio urbano desde hace mucho tiempo por agricultores de origen rural y urbano, desde el cultivo de alimentos es practicado por ellos en áreas propias, públicas y asignadas; pequeños espacios en los que se cultiva una diversidad significativa de alimentos a partir de una transición agroecológica, marcada por un campesinado plural, ya sea en la comercialización a través de alternativas en los mercados locales, así como en el autoconsumo.

Palavras-chave: Transición Agroecológica. Espacios urbanos. Agricultura urbana. Montes Claros. 


\section{Introdução}

A produção de alimentos em áreas urbanas pode ser uma estratégia fundamental e contribui diretamente com a disponibilidade de alimentos frescos, saudáveis e nutritivos produzidos de forma agroecológica e a preços mais justos para a população da cidade. A AU engloba as práticas produtivas destinadas ao autoconsumo e/ou ao comércio de sua produção excedente no mercado local, na medida em que é praticada em diferentes tipos de terrenos urbanos, com diferentes localizações e com variadas ocupações de áreas de terras públicas ou privadas (COUTINHO, 2011).

Além disso, tem a capacidade de tornar-se fundamental na melhoria da segurança e soberania alimentar e nutricional das pessoas e promovendo o aproveitamento dos "espaços vazios" da cidade. A AU está ligada, portanto, à preservação e manutenção da biodiversidade no espaço urbano, por exemplo, o plantio de árvores, jardins, criação de pequenos animais (aves, suínos etc.) e plantas ornamentais.

Contudo, a prática do desenvolvimento da AU tem figurado como uma alternativa de produção principalmente das espécies destinadas à alimentação (hortaliças, frutas, verduras, grãos etc.). A prática da AU está presente na vida de diversos moradores urbanos, principalmente os que são vindos do processo de migração do rural para o urbano, reproduzindo seus hábitos e costumes, assim como preservando seu patrimônio cultural herdado do meio rural.

Nesse sentido, o objetivo desse trabalho mostrar a importância dessa prática de produção de alimentos na cidade de Montes Claros-MG, partindo de aporte teórico através de outros trabalhos já desenvolvidos sobre essa temática, evidenciando os aspectos relacionados a produção e comercialização dos produtos da AU na cidade.

Tem-se alguns estudos que foram realizados acerca da Agricultura Urbana em Montes Claros, entre o período de 2009 a 2021, que mostram a importância dessa prática em relação a produção de alimentos, principalmente, hortaliças, frutíferas e plantas medicinais, sendo cultivadas em nos quintais de casa, lotes vagos e áreas públicas.

Também, de forma sazonal, foi encontrado o cultivo de milho e feijão, cujo plantio obedece ao regime das chuvas da região norte-mineira, que são concentradas no período de novembro a março. Além disso, verificou-se a criação de animais, muitos deles transitando e pastando nas vias públicas, a saber: cavalos, vacas, cabras, galinhas e porcos (OLIVEIRA, 2011).

Assim, pode-se reafirmar o papel histórico do campesinato e a campesinidade mesmo no espaço urbano. Por isso, cabe salientar que há uma agrobiodiversidade marginalizada no bojo das políticas públicas, sobretudo, na América Latina, África e Ásia (ALTIERI, 2012). Nesse contexto, o debate sobre a AU deve contemplar o papel do campesinato frente à produção de alimentos para além da ordem capitalista (BOVE; DUFOUR, 2001; SANTOS, 2010; PLOEG, 2016).

\section{1 - As características da agricultura urbana na cidade de Montes Claros-MG}


Neste tópico, busca-se salientar os principais autores, estudos, análises conceituais e algumas definições e características da AU que vem sendo desenvolvida em Montes Claros-MG, em conformidade com o processo da expansão urbana da cidade.

A cidade de Montes Claros, é o principal centro econômico da região norte de Minas Gerais. A cidade de Montes Claros ocupa uma área de $145 \mathrm{~km}^{2}$, onde vive uma população de 338.381 habitantes, esse total corresponde a $94 \%$ da população total do município (IBGE, 2010).

Nesse contexto, a cidade apresenta um setor educacional bastante desenvolvido, no qual há o destaque do ensino superior composto por duas Universidades Públicas - Universidade Estadual de Montes Claros (UNIMONTES) e Instituto de Ciências Agrárias da Universidade Federal de Minas Gerais (UFMG) - além de onze faculdades particulares. Essa estrutura faz da cidade um importante centro educacional do Norte, Noroeste, Vale Jequitinhonha e sul da Bahia. (LEITE, 2006).

A economia da cidade, baseia-se principalmente, no comércio, que emprega grande parte da população de Montes Claros, tendo também como fonte de serviço, a instalação de algumas indústrias de grande importância, tais como: Nestlé, Novo Nordisk, COTEMINAS e Lafarge.

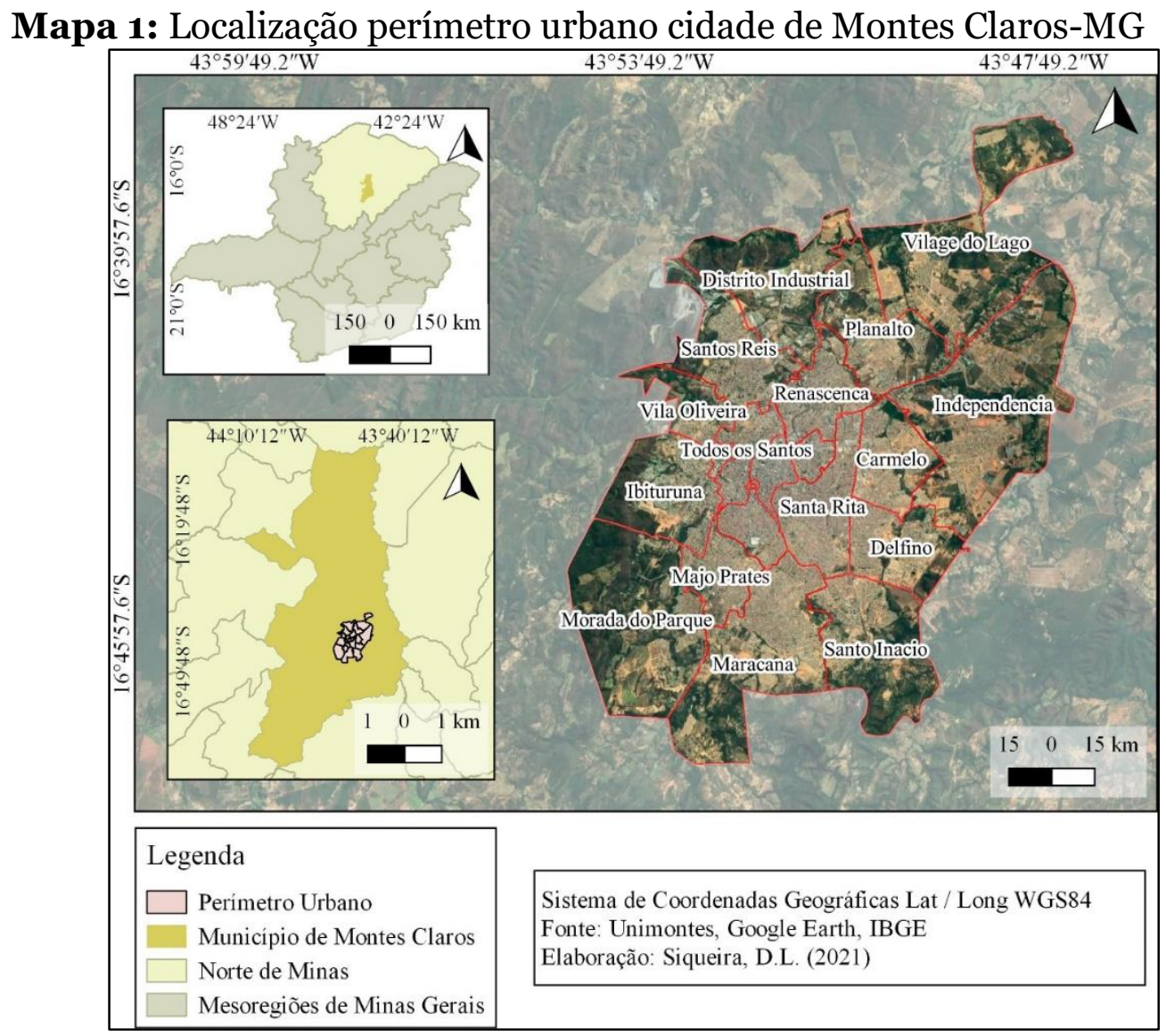

Fonte: Os autores, 2021.

Nesse sentido, a cidade por ser considerada um polo na promoção de serviços, sua população é composta por habitantes que migraram de outros 
municípios para a cidade de Montes Claros, em busca de oportunidades de emprego e educação. Assim, muitas pessoas que possuem origem rural vêm desenvolvendo a prática de AU no espaço urbano, desenvolvendo as práticas de produção de alimentos e criação de pequenos animais.

A AU é uma atividade que vem sendo desenvolvida de forma individual e coletiva na cidade, os agricultores(as) utilizam áreas próprias, empresta e públicas para praticar a AU, a produção de alimentos é utilizada para o autoconsumo e a comercialização no mercado local, principalmente nas feiras de bairros e mercado municipal da cidade. O esforço é mostrar os principais benefícios das atividades da AU para o espaço urbano e para os(as) agricultores(as), evidenciando aspectos sociais, ambientais e econômicos que, ao mesmo tempo, fazem uma relação entre a produção de alimentos desses(as) agricultores(as) por meio de práticas produtivas baseadas nos princípios da transição agroecológica e na importância do uso de áreas ociosas urbanas públicas e privadas para a ampliação da $\mathrm{AU}$, possibilitando, consequentemente, a ampliação das áreas disponíveis para a produção de alimentos na cidade.

A prática de $\mathrm{AU}$ desenvolvida na cidade está baseada nos princípios agroecológicos que diferem do modelo da agricultura convencional. Assim, a produção de alimentos na cidade pode ser uma alternativa para a população consumir alimentos mais saudáveis.

Nesse sentido, Altieri (1998, p. 18-19) define que:

\begin{abstract}
A produção sustentável em um agroecossistema deriva do equilíbrio entre plantas, solos, nutrientes, luz solar, umidade e outros organismos coexistentes. O agroecossistema é produtivo e saudável quando essas condições de crescimento ricas e equilibradas prevalecem, e quando as plantas permanecem resilientes de modo a tolerar estresses e adversidades. Às vezes, as perturbações podem ser superadas por agroecossistemas vigorosos, que sejam adaptáveis e diversificados o suficiente para se recuperarem passado o período de estresse. Ocasionalmente, os agricultores que empregam métodos alternativos podem ter de aplicar medidas mais drásticas (isto é, inseticidas botânicos, fertilizantes alternativos) para controlar pragas específicas ou deficiências do solo. A agroecologia engloba orientações de como fazer isso, cuidadosamente, sem provocar danos desnecessários ou irreparáveis. Além da luta contra as pragas, doenças ou problemas do solo, o agroecologista procura restaurar a resiliência e a força do agroecossistema. Se a causa da doença, das pragas, da degradação do solo, por exemplo, for entendida como desequilíbrio, então o objetivo do tratamento agroecológico é restabelecê-lo. O tratamento e a recuperação são orientados por um conjunto de princípios específicos e diretrizes tecnológicas.
\end{abstract}

O levantamento bibliográfico sobre o tema "transição agroecológica" revela que existem diferentes análises sobre o assunto, cuja abordagem perpassa as diferentes áreas do conhecimento. Biase (2010) propõe uma agroecologia plena e para isso aponta as contribuições da Ecologia, Sociologia e Agronomia., entende-se que o assunto tem um amplo debate, que envolve duas dimensões - uma dimensão relacionada mais aos aspectos produtivos, envolvendo a técnica e a tecnologia, e, a outra dimensão, voltada mais para os conceitos filosóficos da transição, abordando principalmente a harmonização ser humano e natureza. 
Nesse caso, essa discussão mais ampla não é o foco dessa pesquisa. Para mais informações sugere-se: Caporal (2009), Schmitt (2013) e Timo (2017). Exemplificando melhor as principais características do modelo de produção convencional para o agroecológico, o Quadro 1 mostra de forma clara essas diferenciações.

Quadro 1: Diferenciação entre o modelo de produção convencional e o modelo de produção

\begin{tabular}{|c|c|}
\hline Sistema agroquímico industrial & Sistema agroecológico \\
\hline Tecnologia de produtos (aquisição de insumos) & $\begin{array}{l}\text { Tecnologia de processos (envolve a relação: } \\
\text { planta, solo e ambiente) }\end{array}$ \\
\hline Uso de pesticidas & $\begin{array}{l}\text { Resistência natural e uso de produtos } \\
\text { alternativos }\end{array}$ \\
\hline Adubos solúveis & Adubos orgânicos e rochas moídas \\
\hline Baixo teor de matéria orgânica & Rico em matéria orgânica \\
\hline Falta de manejo e cobertura do solo & Mantém a cobertura do solo \\
\hline Monocultura & Rotação e Biodiversidade \\
\hline $\begin{array}{l}\text { Erosão do solo, empobrecimento quanto a } \\
\text { húmus e vida microbiana }\end{array}$ & $\begin{array}{l}\text { Aumento de húmus, microrganismos e insetos } \\
\text { benéficos }\end{array}$ \\
\hline Erradicação dos inimigos naturais & Equilíbrio do solo e ambiente \\
\hline Desequilíbrio mineral & Equilíbrio nutricional \\
\hline Alimentos contaminados & Alimentos sadios \\
\hline Contaminação e deterioração do ecossistema & Ecossistema equilibrado e saudável \\
\hline Descapitalização & Sistema autossustentável \\
\hline
\end{tabular}

Fonte: PADOVAN, 2006, p. 39.

O Quadro 1 mostra os principais elementos que diferenciam o sistema de produção convencional do sistema agroecológico. O sistema de produção convencional é baseado em tecnologias que incluem o uso intensivo de produtos químicos, ampla mecanização, variedades de sementes geneticamente modificadas e o cultivo extensivo de monocultoras. 
Nesse sistema, os agricultores ficam reféns das sementes híbridas e dos agrotóxicos, que acabam acarretando danos irreparáveis ao solo, rios, nascentes etc., com base em outros princípios, no sistema agroecológico, na utilização dos recursos naturais e nas práticas de adubação natural, promovendo o equilíbrio do solo e do meio ambiente. Consequentemente, é possível aumentar a biodiversidade e produzir alimentos mais saudáveis.

Segundo Siliprandi (2002), as evidências dos resultados da produção de alimentos de base agroecológica, são fruto dos novos métodos trabalhados com base nos princípios norteadores da agroecológica e tecnologias sociais de acesso à água, construídas de forma participativa com os próprios agricultores(as), ONGs e algumas organizações locais.

\subsection{As práticas de Agricultura Urbana no espaço urbano}

No cenário atual, é indispensável fazer reflexões sobre o processo acelerado da produção do espaço que vem ocorrendo, principalmente no século XXI, desenvolvidas pelas relações capitalistas por meio de investimentos em empreendimentos imobiliários nas áreas urbanas, transformando o espaço urbano em mercadoria promovendo a apropriação privada dos bens e serviços que são instituídos nas cidades (NASCIMENTO, 2016).

Nesse contexto, por meio das práticas da agricultura urbana, é possível promover a criação de ecossistemas agrícolas no intuito de produzir alimentos. Madaleno (2002, p. 170) afirma que “[...] o espaço tem, no geral, um valor de uso [...] finalmente, esparciam-se as explorações agrícolas pela periferia, em lotes quer individualizados [...] quer comunitários [...] de muito maiores dimensões, normalmente superiores ao hectare $[\ldots] ”$.

Esse tipo de prática vem ganhando notoriedade por meio do envolvimento de pessoas que vêm desenvolvendo a AU em áreas públicas ou privadas, ao mesmo tempo, cresce o número de pessoas que estão cultivando alimentos nos quintais de casa, aproveitando alternativas de espaços para produzir. Essas iniciativas no espaço urbano promovem o envolvimento desses sujeitos no processo de produção e consumo dos alimentos.

Entender o fenômeno de transformação da cidade após a Revolução Industrial (final do século XVIII em diante), tanto na escala temporal, quanto espacial, é necessário, pois desse processo surgiram novas relações sociais, novas tecnologias, modificações das áreas urbanas, relações econômicas, proporcionando uma reconfiguração do espaço urbano em praticamente todas as regiões do Brasil. Esse processo de mudanças é um grande desafio para a ciência geográfica entender e analisar como essas mudanças drásticas que ocorrem nas cidades são conduzidas por meio do processo capitalista (CARLOS, 2015).

Esse processo de produção e reprodução do espaço vem causando desigualdades e contradições no âmbito das cidades. De modo semelhante, Spósito (1988) salienta que a cidade passou por um intenso processo de urbanização por meio do sistema capitalista que segue se reinventando, representado pela modernização da agricultura, pela expansão do comércio, pela implantação da 
atividade industrial e pela importância política na localização da sede administrativa do poder público.

Corroborando com os contextos supracitados, a produção e a reestruturação do espaço urbano, ocorrem por meio de interesses do capital que investem sob a perspectiva do sistema financeiro nas definições da estrutura urbana, e na representação das transformações e das contradições existentes entre o centro e a periferia na dinâmica da cidade (ALVES, 2011).

Segundo Veiga (2002), a existência de atividades agrícolas em meio urbano é resultado de um processo de urbanização mal planejado e excludente, em que os atores envolvidos (a maioria migrantes rurais), ao ocuparem os múltiplos espaços das cidades, integram-se e reproduzem nela seus modos de vida.

Com o intuito de pensar alternativas para esses problemas urbanos que vêm surgindo na contemporaneidade, Costa (1988, p. 890) profere que:

Para a efetivação desses princípios e o enfrentamento dos problemas urbanos propõe a criação de mecanismos que garantam à população a manutenção de direitos já adquiridos e a participação no estabelecimento de prioridades, bem como permitam ao poder público penalizar a especulação imobiliária pelo uso improdutivo do solo e dispor de áreas urbanas de forma que uma mais justa ocupação do espaço possa ser obtida.

Assim, reafirma-se que a AU pode cooperar com a produção do espaço urbano ressignificando áreas dentro desse complexo espaço e trazendo consigo um conjunto de fatores sociais, econômicos, ambientais e culturais que são pertinentes na agricultura (JACINTO et al., 2012).

Nesse sentido, existe a necessidade de pensar a AU na perspectiva de promover uma nova reconfiguração e produção do espaço que inclua as práticas de produção de alimentos aliados aos princípios da sustentabilidade para promover o uso e a função social dos vazios urbanos. "A agricultura urbana é meio de sobrevivência tanto dos 'camponeses desterrados' quanto dos 'operários pobres'. Famílias de trabalhadores nas metrópoles, diante da cidade que tudo lhes nega, tramam processos, traçam novos caminhos, reinventam caminhos, fazem da agricultura um modo de vida” (MOREIRA, 2008, p. 243).

Vale ressaltar, que na literatura já há pesquisas, discussões e análises sobre o papel importante que a AU pode proporcionar em relação à produção do espaço; há vários estudos na literatura estrangeira abordando aspectos relacionados ao panorama de expansão da $\mathrm{AU}$, a relação entre $\mathrm{AU}$ e segurança alimentar e a importância do poder público na elaboração de políticas públicas de apoio e incentivo à AU.

Sobre a importância do desenvolvimento da AU, nota-se que isso vem ocorrendo desde a década de 1980 no Brasil. Nesse sentido, destaca-se, nas capitais brasileiras, iniciativas de agricultura urbana financiadas pela sociedade civil, pelas universidades e por setores privados, assim como pelos três níveis de governo federal, estadual e municipal - e, também, identificaram vários movimentos sociais urbanos e rurais que apoiam e desenvolvem práticas da agricultura urbana (SANTANDREU; LOVO, 2007). 
Na prática, o cultivo de alimentos em espaços urbanos é uma realidade que está sendo praticada nos espaços urbanos, principalmente por meio das experiências de produção de hortas, seja a partir de iniciativas comunitárias ou individuais, dando novos usos aos espaços urbanos e os reconfigurando.

\subsection{Agricultura Urbana em Montes Claros-MG}

Analisando os estudos desenvolvidos na cidade sobre AU, Pinheiro (2017) e Siqueira (2021) observam que o desenvolvimento das práticas de AU apresentado nas pesquisas apontam que a AU em Montes Claros vem sendo praticada por vários agricultores(as) em diferentes tipos de áreas e que a AU não é praticada somente em áreas com população de baixa renda.

Existem várias experiências de produção de hortaliças, frutíferas e plantas medicinais desenvolvidas por agricultores(as), a AU é praticada de forma agroecológica, sem o uso de qualquer tipo de insumos químicos, utilizando somente recursos naturais, no processo de adubação e no controle de doenças e pragas. Essa produção agroecológica é um diferencial da AU que vem sendo praticada nos espaços urbanos de Montes Claros.

Essa produção de alimentos no espaço urbano da cidade é utilizada para o autoconsumo e como fonte marcante de geração de renda. Além da comercialização da produção, os produtos agrícolas urbanos são destinados ao próprio consumo e são doados para parentes, vizinhos e projetos sociais (OLIVEIRA, 2011).

Assim, de acordo com Siqueira (2021, p. 91),

Á produção das hortaliças é uma das principais atividades praticadas pelos/as agricultores/as da cidade de Montes Claros. A diversidade de variedades das hortaliças cultivadas é algo que mostra o papel importante da $\mathrm{AU}$ a respeito da produção de alimentos diversos e agroecológicos que vem sendo praticada em pequena escala pelos/as entrevistados/as no espaço urbano.

Conforme Oliveira (2011), a Agricultura Urbana encontrada na cidade de Montes Claros é um exemplo da integração dos hábitos e das práticas do rural no ambiente urbano através da perspectiva do continuum.

Nesse sentido, para Pereira (2017, p. 153):

A Agricultura Urbana apresenta diversas potencialidades em Montes Claros, das quais destacam-se: o uso de quintais e de lotes vagos; o plantio e cultivo pode ser uma terapia para os agricultores urbanos; a geração de emprego e renda; a produção para o autoconsumo e para comercialização; a utilização de matérias orgânicas na produção de hortaliças; a criação e a manutenção de áreas verdes nas cidades; o uso de água de poços artesianos e da companhia de saneamento; e a manutenção das relações urbanas-rurais através de laços socioculturais.

As práticas de produção da AU podem trazer diversos benefícios para os agricultores(as) e para a sociedade urbana devido a produção de alimentos agroecológicos e geração de renda, bem como por conta da criação de circuitos curtos de comercialização na cidade. 
As práticas de AU que estão sendo desenvolvidas em alguns bairros da cidade de Montes Claros, englobam várias atividades ligadas à produção de alimentos, ou seja, pode ser uma atividade estratégica para o fornecimento de alimentos, garantindo a segurança alimentar e nutricional de várias famílias que moram na cidade e vivem em situação de vulnerabilidade social.

Além disso, é uma forma importante de reprodução do campesinato ou parte de um modo de vida que está sendo reproduzido na cidade, que se expressa de diversos formatos, ou seja, por meio da organização do trabalho, seja coletivo ou individual, inserção nas alternativas de mercados locais e trocas de experiências etc.

\section{Considerações Finais}

O desenvolvimento da AU no espaço urbano tem vários desafios, porém, observa-se que existem várias experiências de práticas de AU na cidade. Todo esse desafio da AU segue em construção nas pequenas cidades, aspectos que são retratados em pesquisas das Universidades, que mostram o papel importante da agricultura urbana em relação à segurança alimentar e à geração de renda para as famílias.

Assim, nota-se o potencial da agricultura urbana como uma estratégia social, territorial, ambiental e econômica ao recriar possibilidades a partir da produção de alimentos em diálogo com uma transição agroecológica. Reitera-se ainda, que a luta pela transição agroecológica também está presente na pauta dos movimentos socioterritoriais para construção de políticas públicas, envolvendo os consumidores, a universidade e a sociedade como um todo. Nesse devir, a agricultura urbana poderá representar um caminho importante que remete à soberania e a segurança alimentar.

\section{Referências}

ALTIERI, Miguel. Agroecologia: as bases científicas para uma agricultura sustentável. São Paulo, Rio de Janeiro; Expressão Popular, ASPTA, 2012.

ALTIERI, M. A. Agroecologia - a dinâmica produtiva da agricultura sustentável. Porto Alegre: Editora da Universidade Federal do Rio Grande do Sul, 1998. 110 p.

ALVES, L. A. Reestruturação urbana e criação de novas centralidades: considerações sobre os shoppings centers. Caminhos de Geografia, Uberlândia, v. 12, n. 37, 2011. p. 171-184.

BIASE, L. de. Agroecologia, campesinidade e os espaços femininos na unidade familiar de produção. Dissertação de Mestrado. Piracicaba, CENA ESALQ USP, 2010.

BOVÉ, J; DUFOUR, F. O mundo não é uma mercadoria: camponeses contra a comida ruim. São Paulo: Editora UNESP, 2001

CARLOS, A. F. A. A reprodução do espaço urbano como momento da acumulação capitalista. Crise urbana, v. 1, p. 25-36, 2015. 
COSTA, H. S. M. A reforma urbana e a busca da cidadania. Revista Indicador, $\mathrm{n}$. 27. Belo Horizonte: ALEMG, 1988.

COUTINHO, M. N.; COSTA, H. S. M. Agricultura urbana: prática espontânea, política pública e transformação de saberes rurais na cidade. Geografias, v. 7, n. 2, p. 81-97, 2011.

IBGE. Enciclopédia dos Municípios Brasileiros. Rio de Janeiro. IBGE, 1960, 1970, 1980, 1991 e 2000.

LEITE, M. E. Geoprocessamento aplicado ao estudo do espaço urbano: o caso da cidade de Montes Claros - Minas Gerais. 2006. 177p. Dissertação (Mestrado em Geografia). Instituto de Geografia, Universidade Federal de Uberlândia, Uberlândia, 2006.

MOREIRA, C. Trajetórias contemporâneas da agricultura urbana. In: HISSA, Cássio Eduardo Viana (Org.). Saberes ambientais: desafios para o conhecimento disciplinar. Belo Horizonte: Ed. UFMG, 2008. p. 243-281.

NASCIMENTO, D. M. As políticas habitacionais e as ocupações urbanas: dissenso na cidade. Cadernos Metrópole, v. 18, n. 35, p. 145-164, 2016.

OLIVEIRA, I. M. de; CARNEIRO, M. de F. B. Tradições rurais em vidas urbanas: a Agricultura Urbana no bairro Vila Anália, Montes Claros/MG. Revista Cerrados, v. 10, n. 01, p. 101-127, 2012.

OLIVEIRA, Igor Martins de. Tradições Rurais em Vidas Urbanas. A Agricultura Urbana no Bairro Vila Anália, Montes Claros/MG. 2011. 87f. TCC (Trabalho de Conclusão de Curso, Graduação em Geografia). Universidade Estadual de Montes Claros-Unimontes, Montes Claros, 2011.

PEREIRA, L. A. G.; CARNEIRO, M. de F. B.; DE OllVEIRA, I. M. ESPACIALIZAÇÃO DA AGRICULTURA URBANA NA CIDADE DE MONTES CLAROS, MINAS GERAIS, BRASIL. Revista Desenvolvimento Social, v. 21, n. 1, p. 143-156, 2017.

PINHEIRO, C. E. F. Agricultura urbana em Montes Claros, MG: funcionalidades, produção e comercialização. 2017. Instituto de Ciências Agrárias da UFMG, 2017. 99 f.: il. Dissertação (Mestrado em Planejamento Urbano e Regional/Demografia) - Universidade Federal de Minas Gerais/Universidade Estadual de Montes Claros.

PLOEG, Jan Douwe van der. Camponeses e a arte da agricultura: um manifesto Chayanoviano. São Paulo; Porto Alegre: Ed. Unesp; Ed. UFRGS, 2016.

SANTOS, T. A. Agroecologia como prática social: feiras agroecológicas e insubordinação camponesa na Paraíba. 2010. Dissertação de Mestrado. SãoPaulo: FFLCH-USP, 2010.

SILIPRANDI, E. Desafios para a extensão rural: o "social" na transição agroecológica. Rev. Agroecologia e Desenvolvimento Rural Sustentável, Porto Alegre, v.3, n.3, Jul/Set 2002.

SPOSITO, M. E. B. Capitalismo e urbanização. São Paulo: Contexto, 1988. 